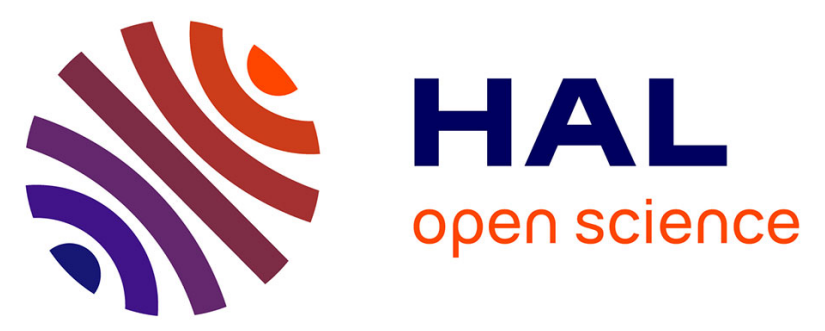

\title{
Light-induced controlled free radical polymerization of methacrylates using iron-based photocatalyst in visible light
}

\author{
Ankushi S Bansal, Pawan S Kumar, Chandra S Sharma, Siddharth S Ray, \\ Suman L Jain
}

\section{To cite this version:}

Ankushi S Bansal, Pawan S Kumar, Chandra S Sharma, Siddharth S Ray, Suman L Jain. Lightinduced controlled free radical polymerization of methacrylates using iron-based photocatalyst in visible light. Journal of Polymer Science Part A: Polymer Chemistry, 2015, 53, pp.2739 - 2746. 10.1002/pola.27744 . hal-01456560

\author{
HAL Id: hal-01456560 \\ https://hal.science/hal-01456560
}

Submitted on 5 Feb 2017

HAL is a multi-disciplinary open access archive for the deposit and dissemination of scientific research documents, whether they are published or not. The documents may come from teaching and research institutions in France or abroad, or from public or private research centers.
L'archive ouverte pluridisciplinaire $\mathbf{H A L}$, est destinée au dépôt et à la diffusion de documents scientifiques de niveau recherche, publiés ou non, émanant des établissements d'enseignement et de recherche français ou étrangers, des laboratoires publics ou privés. 


\title{
Light-Induced Controlled Free Radical Polymerization of Methacrylates Using Iron-Based Photocatalyst in Visible Light
}

\author{
Ankushi Bansal, ${ }^{1}$ Pawan Kumar, ${ }^{1}$ Chandra D. Sharma, ${ }^{2}$ Siddharth S. Ray, ${ }^{1}$ Suman L. Jain ${ }^{1}$ \\ ${ }^{1}$ Chemical Sciences Division, CSIR-Indian Institute of Petroleum, Dehradun 248005, Uttarakhand, India \\ ${ }^{2}$ Analytical Sciences Division, CSIR Indian Institute of Petroleum, Dehradun 248005, Uttarakhand, India \\ Correspondence to: S. S. Ray (E-mail: ssray@iip.res.in) or S. L. Jain (E-mail: suman@iip.res.in)
}

Received 25 February 2015; accepted 16 June 2015; published online 27 July 2015

DOI: $10.1002 /$ pola.27744

ABSTRACT: A novel visible light mediated catalytic system based on low cost iron complex, that is, $\mathrm{Fe}(\mathrm{bpy})_{3}(\mathrm{PF})_{6}$ photocatalyst that initiates and control the free radical polymerization of methacrylates using ethyl $\alpha$-bromoisobutyrate (EBriB) as an initiator and 20 watt LED as light source is developed. The polymerization is initiated with turning the light on and immediately terminated by turning the light off. In addition, the molecular weight of polymer can be varied by changing the ratio of monomer and initiator. The merits of the present methodology lie in the use of low cost less precious, highly abun- dant iron-based photocatalyst, avoidance of sacrificial donor and need of lower catalyst amount under visible light. The optimum amount of catalyst and initiator were established and successful polymerization of various methacrylates was achieved under the optimized polymerization conditions. (C) 2015 Wiley Periodicals, Inc. J. Polym. Sci., Part A: Polym. Chem. 2015, 53, 2739-2746

KEYWORDS: monomers; photochemistry; photopolymerization
INTRODUCTION Free radical polymerization is one of the most widely employed polymerization techniques which have been successfully applied in the preparation of paints, high molecular weight poly(methyl methacrylate) for safety glass (Plexiglas ${ }^{\circledR}$ ), and foamed poly (styrene). ${ }^{1}$ The conventional approaches for initiating radical polymerization reactions involve thermal decomposition of azo-compounds (e.g., dialkyldiazenes, AIBN), peroxides (e.g., diaroyl peroxides), organometallic compounds (e.g., trialkyltin hydride) etc. However, requirement of higher reaction temperatures is one of the main obstacles associated with these processes. In contrast, photo-induced initiation provides a better control in the radical polymerization reactions under ambient temperature. The effect of light in ATRP was first reported by Guan and Smart in 2000 in the $\mathrm{CuCl} / 2,2$-bipyridine catalyzed polymerization of MMA using 2,2-dichloroacetophenone as an initiator under visible light irradiation. ${ }^{2}$ Subsequently a number of reports have been published in the area of visible-light mediated controlled free radical polymerizations. ${ }^{3}$ Yagci et al. reported eosin Y and erythrosine B as photosensitizer and $\mathrm{Cu}(\mathrm{II})$ chloride as catalyst for polymerization of MMA in the presence of visible light and initiator. ${ }^{4,5}$ Choi et al. ${ }^{6}$ reported a novel free radical polymerization initiated and controlled by visible light photocatalysis using $\mathrm{Ru}(\mathrm{bpy})_{3} \mathrm{Cl}_{2}$ as catalyst and tertiary amines, i.e., ${ }^{\mathrm{i}} \mathrm{Pr}_{2}$ -
Net) as a sacrificial donor. Hawker et al. ${ }^{7}$ studied the visible light-stimulated living radical polymerization of MMA using Ir(III) complex with alkyl bromide initiator in the absence of sacrificial donor. Very recently an efficient metal free light mediated ATRP process using an organic-based photoredox catalyst has been developed. ${ }^{8}$

Owing to the growing economic and environmental issues, the uses of low cost visible light active photocatalytic materials are desired. ${ }^{9-12}$ Iron is the second most abundant metal on the earth crust (4.7\%), which is relatively less toxic, less expensive and can be established to be ideal metal catalyst for various applications. In this regard, iron-based photocatalysts mainly iron(II) bipyridine complexes have widely been used for dye degradation, photo-oxidation and reduction reactions. ${ }^{13-15}$ However, the use of iron complexes for visible light initiated and controlled free radical polymerization is rarely known and needs to be developed from sustainable chemistry prospective. ${ }^{16-21}$

In continuation to our ongoing efforts on controlled polymerization $^{22}$ and visible light assisted chemical transformations, ${ }^{23,24}$ herein we report the first successful application of iron-based photocatalyst i.e. $\left[\mathrm{Fe}(\mathrm{bpy})_{3}\right]\left(\mathrm{PF}_{6}\right)_{2}$ (Fig. 1) for the controlled radical polymerization without using sacrificial donor under visible light irradiation. We have proposed the

Additional Supporting Information may be found in the online version of this article.

(c) 2015 Wiley Periodicals, Inc.

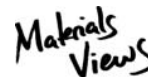




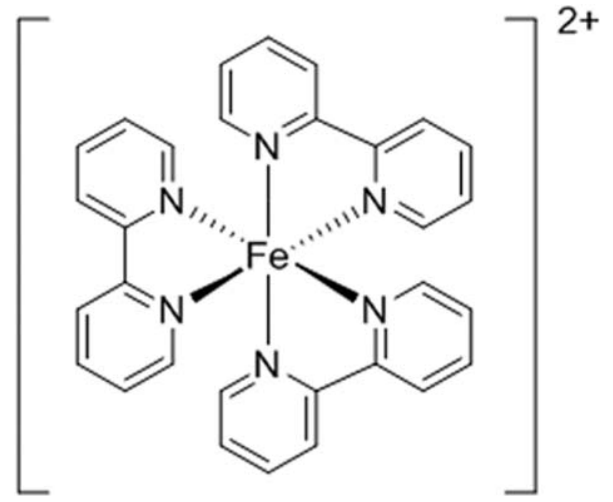

FIGURE 1 The photoredox catalyst $\left[\mathrm{Fe}(\mathrm{bpy})_{3}\right]^{+2}\left(\mathrm{PF}_{6}\right)_{2} 1$.

mechanism of radical polymerization as depicted in Scheme 1. The iron(II)bipyridyl complex, [Fe(II)], absorbs visible light to give excited Fe(II)* state. We assumed that this excited $\mathrm{Fe}(\mathrm{II})^{*}$ species would donate electron to alkyl bromide initiator and promote homolysis of $\mathrm{C}-\mathrm{Br}$ bond of ethyl $\alpha$-bromoisobutyrate to generate alkyl radical which could initiate the polymerization reaction. ${ }^{25-28}$ The originated Fe(III) could react with propagating radical to regenerate Fe(II) complex in ground state along with a dormant polymer chain having bromo end group. This process goes on to give a controlled radical polymerization. The merits of the developed system lie in the use of visible light that control the polymerization as well as molecular weight. Furthermore, iron (II) bipyridine complex can be considered superior than ruthenium and iridium based photocatalysts with respect to the low cost and easy accessibility of the iron.

\section{EXPERIMENTAL}

\section{Materials}

Iron (II) chloride (98\%), 2,2'-bipyridine (99\%), ammonium hexafluoro phosphate (99.9\%) purchased from Aldrich were of analytical grade and used without further purification. Methyl methacrylate (MMA, 99\%), benzyl methacrylate (BMA, 99\%), glycidyl methacrylate (GMA, 97\%) was purchased from Sigma-Aldrich and purified by passing through a neutral aluminum oxide column. Ethyl 2-bromoisobutyrate (EBriB, 98\%) from Sigma-Aldrich was distilled over $\mathrm{CaH}_{2}$ under high vacuum and stored at $-20{ }^{\circ} \mathrm{C}$ under $\mathrm{N}_{2}$ atmosphere. Dimethylformamide (DMF, 99.5\%) from Sigma-Aldrich was dried with $\mathrm{CaH}_{2}$ and distilled under high vacuum for further purification. All other chemicals were of A.R. grade and used without further purification. Iron(II)bipyridine complex was synthesized by following the literature method $^{29}$ (See supporting information).

\section{General Procedure of Visible Light Induced Polymerization}

A dried double necked round bottom flask, equipped with a magnetic stir bar and fitted with a Teflon screw cap septum, was charged with MMA (2 mL, $0.0188 \mathrm{~mol}$ ), iron complex 1 (0.06-0.003 mol \%) and DMF (2 mL, monomer/solvent $=1 / 1$ $\mathrm{v} / \mathrm{v}$ ). The reaction mixture was degassed by freeze-pumpthaw cycles (5 times). The flask was then backfilled with nitrogen and this cycle was repeated three times. To this solution, initiator $\operatorname{EBriB}\left(5.45 \times 10^{-4}-2.73 \times 10^{-4}\right.$ moles $)$ was injected via syringe to commence the polymerization. The reaction mixture was stirred in front of a $20 \mathrm{~W}$ white cold LED lamp (Model No. HP-FL-20W-F-Hope LED Opto-Electric Co. Ltd $\lambda>400 \mathrm{~nm}$ ) and the intensity of light on vessel was found $75 \mathrm{~mW} / \mathrm{cm}^{2}$. An aliquot was then removed from the reaction mixture after regular intervals and polymer was precipitated with large excess of methanol, washed with methanol and then dried overnight. The conversion was determined gravimetrically. The obtained samples were analyzed by GPC to give the number average molecular weight $\left(M_{\mathrm{n}}\right)$, weight average molecular weight $\left(M_{\mathrm{w}}\right)$ and molecular weight distribution $\left(M_{\mathrm{w}} / M_{\mathrm{n}}\right)$ of the polymer.

\section{Characterization and Instruments}

Molecular weight distribution and polydispersity index of synthesized polymers were determined by Gel permeation chromatography using Agilent HPLC/GPC system comprising of 1200 infinity series precision Pump, 1200 Series Diode Array detector and 1260 infinity Evaporative Light Scattering Detector. Polymethyacrylate standards were used for calibration of the system. FT-IR spectra were collected on a Nicolet 8700 FT-IR spectrometer in the region of $4000-400 \mathrm{~cm}^{-1}$. UV-vis absorption spectra of Iron(II) bipyridine complex $\mathbf{1}$ in acetonitrile were recorded with a Perkin-Elmer lambda19 UV-vis-NIR spectrophotometer by using a $10 \mathrm{~mm}$ quartz cell. For calculation of iron content of catalyst, ICP-AES analysis was carried out at inductively coupled plasma atomic emission spectrometer (ICP-AES, PS-3000UV, Leeman Labs). For ICP-AES analysis, $10 \mathrm{mg}$ of each sample was dissolved in $2 \mathrm{~mL}$ of concentrated $\mathrm{HNO}_{3}$, heated and diluted with HPLC grade water up to $10 \mathrm{~mL} .{ }^{1} \mathrm{H}$ NMR spectra were recorded on a Bruker Avance III $500 \mathrm{MHz}$ NMR spectrometer operating at $500.13 \mathrm{MHz}$ resonance frequency for ${ }^{1} \mathrm{H}$. Approximately 5 (w/v \%) of the polymer solution was prepared in $\mathrm{CDCl}_{3}$ (Merck, 99.8\% containing 0.03 vol \% for ${ }^{1} \mathrm{H}$ TMS) for acquiring ${ }^{1} \mathrm{H}$ NMR spectra. For ${ }^{13} \mathrm{C}$ NMR the chemical shifts were reported in $\delta$, ppm relative to signal of the $\mathrm{CDCl}_{3}$ triplet at

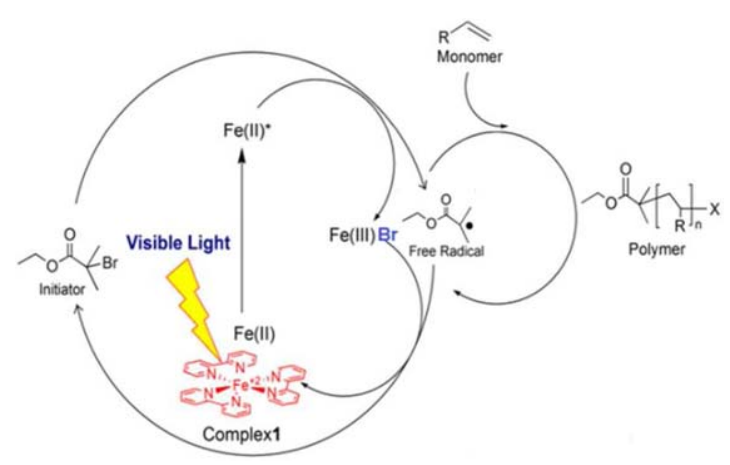

SCHEME 1 Proposed mechanism of visible light induced free radical polymerization of MMA. [Color figure can be viewed in the online issue, which is available at wileyonlinelibrary.com.] 
TABLE 1 Effect of Various Reaction Parameters on Visible-Light Mediated Polymerization of MMA using $\left[\mathrm{Fe}\left(\mathrm{bpy}_{3}\right)_{3}\right]\left(\mathrm{PF}_{6}\right)_{2}$ as Catalyst and Ethyl $\alpha$-bromoisobutyrate as Initiator

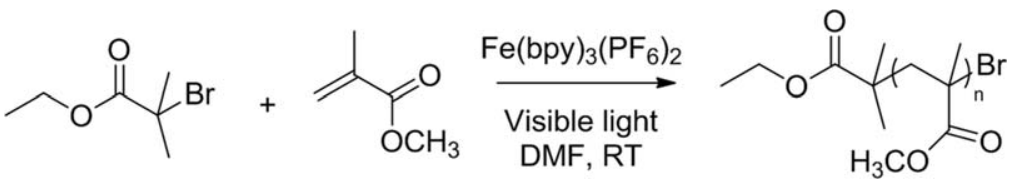

\begin{tabular}{|c|c|c|c|c|c|c|c|}
\hline Entry & $\mathrm{M} / \mathrm{I} / \mathrm{C}$ & Cat. g (moles) & Initiator ( $\mu \mathrm{L} ;$ moles) & $\begin{array}{l}\text { Conv. } \\
(\%)\end{array}$ & $\begin{array}{l}M_{\mathrm{n}, \mathrm{GPC}} \\
(\mathrm{g} / \mathrm{mol})\end{array}$ & $\begin{array}{l}M_{\mathrm{w}} / M_{\mathrm{n}} \\
\text { (PDI) }\end{array}$ & $M_{\mathrm{n}, \text { theor }}$ \\
\hline $1^{\mathrm{a}}$ & $100: 2.9: 0$ & - & $80\left(5.45 \times 10^{-4}\right)$ & - & - & - & \\
\hline $2^{a}$ & 100:0:0.07 & $0.01\left(1.23 \times 10^{-5}\right)$ & - & - & - & - & \\
\hline $3^{b}$ & $100: 2.9: 0.07$ & $0.01\left(1.23 \times 10^{-5}\right)$ & $80\left(5.45 \times 10^{-4}\right)$ & - & - & - & \\
\hline $4^{\mathrm{a}}$ & $100: 2.9: 0.64$ & $0.1\left(1.22 \times 10^{-4}\right)$ & $80\left(5.45 \times 10^{-4}\right)$ & 50 & 98,400 & 2.1 & 1930 \\
\hline $5^{a}$ & $100: 2.9: 0.07$ & $0.01\left(1.23 \times 10^{-5}\right)$ & $80\left(5.45 \times 10^{-4}\right)$ & 39 & 93,500 & 1.62 & 1550 \\
\hline $6^{\mathrm{a}}$ & $100: 2.9: 0.03$ & $0.005\left(6.14 \times 10^{-6}\right)$ & $80\left(5.45 \times 10^{-4}\right)$ & 33 & 68,650 & 1.60 & 1340 \\
\hline $7^{\mathrm{a}}$ & $100: 2.9: 0.003$ & $0.0005\left(6.14 \times 10^{-7}\right)$ & $80\left(5.45 \times 10^{-4}\right)$ & - & - & - & \\
\hline $8^{a}$ & $100: 2.2: 0.03$ & $0.005\left(6.14 \times 10^{-6}\right)$ & $60\left(4.09 \times 10^{-4}\right)$ & 27 & 48,150 & 1.57 & 1440 \\
\hline $9^{a}$ & $100: 1.5: 0.03$ & $0.005\left(6.14 \times 10^{-6}\right)$ & $40\left(2.73 \times 10^{-4}\right)$ & 26 & 87,900 & 1.60 & 1990 \\
\hline $10^{\mathrm{a}}$ & $100: 0.72: 0.03$ & $0.005\left(6.14 \times 10^{-6}\right)$ & $20\left(1.36 \times 10^{-4}\right)$ & 8 & $1,32,350$ & 1.60 & 1300 \\
\hline
\end{tabular}

77.0 ppm. XPS measurements were obtained on a KRATOSAXIS 165 instrument equipped with dual aluminum-magnesium anodes by using $\operatorname{MgK} \alpha$ radiation ( $\mathrm{h} v=1253.6 \mathrm{eV}$ ) operated at $5 \mathrm{kV}$ and $15 \mathrm{~mA}$ with pass energy $80 \mathrm{eV}$ and an increment of $0.1 \mathrm{eV}$. To overcome the charging problem, a charge neutralizer of $2 \mathrm{eV}$ was applied and the binding energy of $\mathrm{C} 1 \mathrm{~s}$ core level $(\mathrm{BE}=4.6 \mathrm{eV})$ of adventitious hydrocarbon was used as a standard. The XPS spectra were fitted by using a nonlinear square method with the convolution of Lorentzian and Gaussian functions, after a polynomial background was subtracted from the raw spectra. Agilent Fluorescence spectrometer was used for the measurement of fluorescence intensity. Photoirradiation was carried out under visible light by using $20 \mathrm{~W}$ white cold LED flood light (model no. HP-FL-20W-F-Hope LED Opto-Electric). Intensity of the light at vessel was measured by intensity meter and was found to be $75 \mathrm{Wm}^{-2}$.

\section{RESULTS AND DISCUSSION}

The visible light mediated free radical polymerization of MMA was carried out by using $20 \mathrm{~W}$ white cold LED light at room temperature. The light flux at the surface of vessel was $75 \mathrm{~mW} / \mathrm{cm}^{2}$. The reaction mixture consisting of MMA, DMF as solvent [MMA/DMF: $1 / 1(\mathrm{v} / \mathrm{v})]$ and EBriB as initiator was irradiated with visible light in the presence of iron complex 1 for $4 \mathrm{~h}$. A number of controlled experiments were carried out with removing an essential component one-by-one, and the results are summarized in Table 1 . First blank reaction was carried out with initiator in the absence of catalyst under visible light; no polymerization was occurred (Table 1, entry 1). Similarly, no was achieved in the absence of initiator having catalyst and polymerization visible light irradia- tion. Furthermore, in the absence of light having all other components, also did not give any polymerization product (Table 1, entries 2 and 3). These findings confirmed that catalyst, initiator and visible light all three were essentially required for the successful polymerization that proceeds through the photocatalytic initiation mechanism as proposed in Scheme 1.

To optimize the reaction conditions, a series of polymerization experiments by changing the molar ratio of MMA/ initiator/catalyst was performed and the results are shown in Table 1 (entries 4-6). In all cases except for entry 4, where higher catalyst amount $\left(0.1 \mathrm{~g}, 1.22 \times 10^{-4}\right.$ mole $)$ was used, the polydispersity index was found to be $\sim 1.6$, which suggested that the visible light induced radical polymerization provided a fairly good distribution of polymers. In case of higher catalyst amount $\left(0.1 \mathrm{~g}, 1.22 \times 10^{-4}\right.$ mole, Table 1 , entry 4), the polydispersity was found to be 2.1 . With decreasing the catalyst concentration from 0.1 to $0.01 \mathrm{~g}$ $\left(1.23 \times 10^{-5}\right.$ mole $), 0.005 \mathrm{~g}\left(6.14 \times 10^{-6} \mathrm{~mole}\right)$, and then $0.0005 \mathrm{~g}\left(6.14 \times 10^{-7}\right.$ mole $)$ with similar amount of initiator $\left(80 \mu \mathrm{L}, 5.45 \times 10^{-4}\right.$ mole $)$, the conversion was decreased from 39 to $33 \%$ and no yield, respectively. Similarly, the $M_{\mathrm{nGPC}}(\mathrm{g} / \mathrm{mol})$ was found to be decreased from 93,468 to 68,638, respectively (Table 1, entry 4-6). As shown in Table 1, PDI in all cases remained almost constant. These findings confirmed that the catalyst amount played a crucial role and by lowering the amount of catalyst, the molecular weight of polymer can be controlled. Further when the concentration of initiator (EBriB) was reduced from 80 to $60 \mu \mathrm{L}\left(4.09 \times 10^{-4}\right)$ and then to $40 \mu \mathrm{L}(2.73 \times$ $10^{-4}$ mole) by using $0.005 \mathrm{~g}$ of catalyst, the $M_{\mathrm{n}, \mathrm{GPC}}(\mathrm{g} / \mathrm{mol})$ was increased from 48,130 to 87,847 without any drastic 


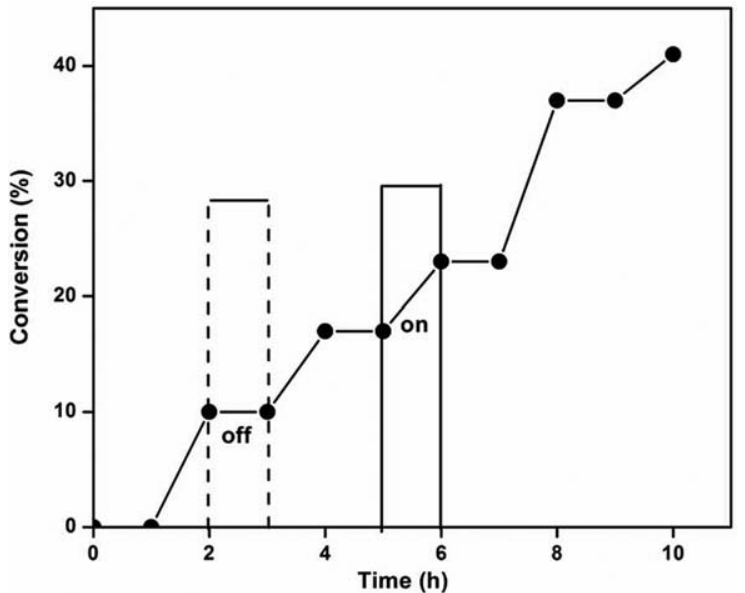

FIGURE 2 Effect of visible light irradiation on the monomer conversion of the free radical polymerization of MMA in 50\% DMF at $25{ }^{\circ} \mathrm{C}$. Reactions conducted with the molar ratio of [MMA]: [EBriB]: $\left[\mathrm{Fe}(\text { bpy })_{3}{ }^{2+}\right]=100: 1.5: 0.03, \mathrm{MMA} / \mathrm{DMF}=1: 1(\mathrm{v} / \mathrm{v})$.

change in PDI. Based on these findings, we fixed $0.005 \mathrm{~g}$ of catalyst and $40 \mu \mathrm{L}$ of initiator as the optimum ratio for the photo-induced controlled polymerization in this study.

To demonstrate the effect of light flux on photocatalytic polymerization of MMA, light was turned on and off at every $1 \mathrm{~h}$ interval and it was observed that when light was turned off there was no polymerization occurred, however as the light was on the polymerization started again as depicted in Figure 2. This "on/off" cycle was repeated several times without any noticeable polymerization reaction in the absence of irradiation (Fig. 2). These results demonstrate that this system is highly responsive to the light and when the light is turned off polymerization stops.

To demonstrate the living nature of the polymerization during these "on/off" cycles, we have plotted $\ln \left([M]_{0} /[M]_{\mathrm{t}}\right)$ versus total exposure time (Fig. 3), and $M_{\mathrm{n}, \mathrm{GPC}}$ versus monomer conversion (Fig. 4). In both cases, linear relationship is obtained. These findings prove that when the light is turned off and polymerization stops, termination of the chain ends

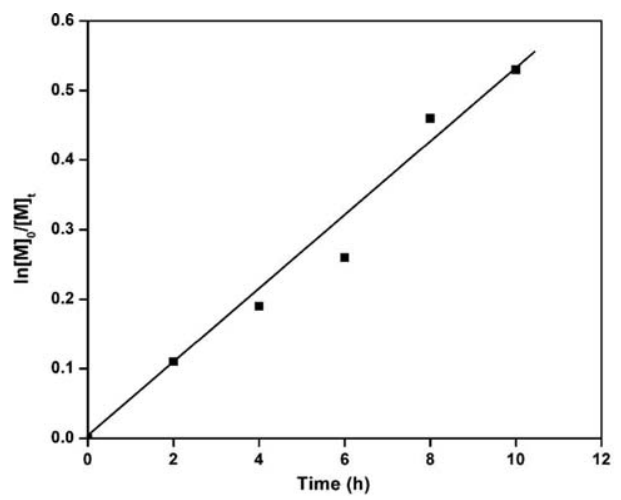

FIGURE 3 Time of light exposure versus $\ln \left([M]_{0} /[M]_{\mathrm{t}}\right)$, with $[M]_{0}$ and $[M]_{\mathrm{t}}$ being the concentrations of monomers at time point zero and $t$, respectively.

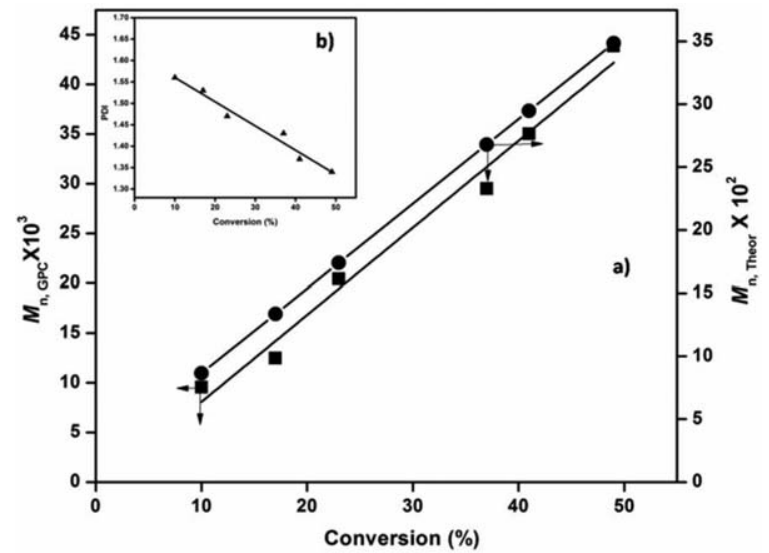

FIGURE 4 (a) Plot of number average molecular weight $M_{\mathrm{n}, \mathrm{GPC}}$ (घ) and $M_{\mathrm{n} \text {,theor }}(\bullet)$ as functions of the monomer conversion at ambient temperature showing linear increase of molecular weight of PMMA with monomer conversion; (b) plot of PDI $\left(M_{w} / M_{n}\right)$ versus monomer conversion showing that PDI decreases from 1.56 to 1.34 with increasing conversion. Reactions conducted with the molar ratio of $[\mathrm{MMA}]:[\mathrm{EBriB}]:\left[\mathrm{Fe}(\mathrm{bpy})_{3}{ }^{2+}\right]=100: 1.5: 0.03, \mathrm{MMA} /$ $\mathrm{DMF}=1: 1(\mathrm{v} / \mathrm{v})$.

is not occurring and in the absence of the light the dormant species is the stable bromo chain end. When these dormant chain ends are re-exposed to light in the presence of the iron catalyst, efficient reactivation of the polymer chain ends is achieved. These "on-off" experiments provide compelling evidence that this process is a photo-controlled radical polymerization, which is highly responsive to visible light as an external stimulus.

Retention of chain end functionality in the polymer is considered to be most important criteria for checking the "livingness." The chain end of PMMA prepared by visible light irradiation using $\mathrm{Fe}(\mathrm{bpy})_{3}(\mathrm{PF})_{6}$ photocatalyst was analyzed by ${ }^{1} \mathrm{H}$ NMR spectroscopy (Fig. 5). The signals observed in ${ }^{1} \mathrm{H}$ NMR at $\delta=4.08-4.2 \mathrm{ppm}$ corresponds to $\mathrm{OCH}_{2}$ protons and $1.12-1.19 \mathrm{ppm}$ corresponds to $2\left(-\mathrm{CH}_{3}\right)$ adjacent to carbonyl group protons of ethyl 2-bromoisbutyrate and peak from 1.30 to $1.33 \mathrm{ppm}$ corresponds to terminal $\mathrm{CH}_{3}$ attached to $\mathrm{OCH}_{2}$. The above NMR chemical shifts of these peaks along with the compared intensities with respect to PMMA peaks confirmed that the initiator moieties of ethyl 2bromoisbutyrate are attached to the polymer chain ends.

Further, the livingness of synthesized polymer was investigated by the chain extension reaction. It is only possible when the retention of the chain end functionality happens to be in synthesized polymer. Thus, the obtained PMMA was used as a macro initiator to conduct a chain extension reaction in terms of copolymerization to check the living character of polymer. Therefore, PMMA $\left(M_{\mathrm{n}, \mathrm{GPC}}=43,850 \mathrm{~g} \mathrm{~mol}^{-1}\right)$ obtained from above reaction was used as predecessor in chain extension experiment with BMA as second monomer. We obtained PMMA-b-PBMA copolymer by same photopolymerization. As shown in GPC (Fig. 6), there is a shift of PMMA $\left(M_{\mathrm{n}, \mathrm{GPC}}=43,850 \mathrm{~g} \mathrm{~mol}^{-1}\right)$ to higher molecular in 
a)

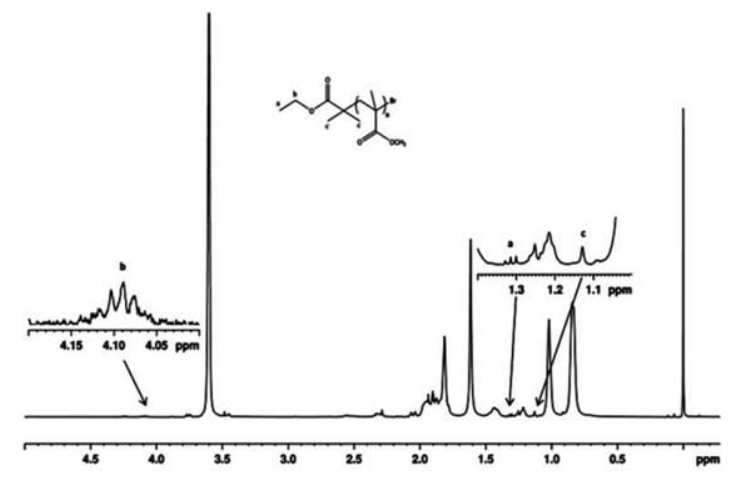

b)

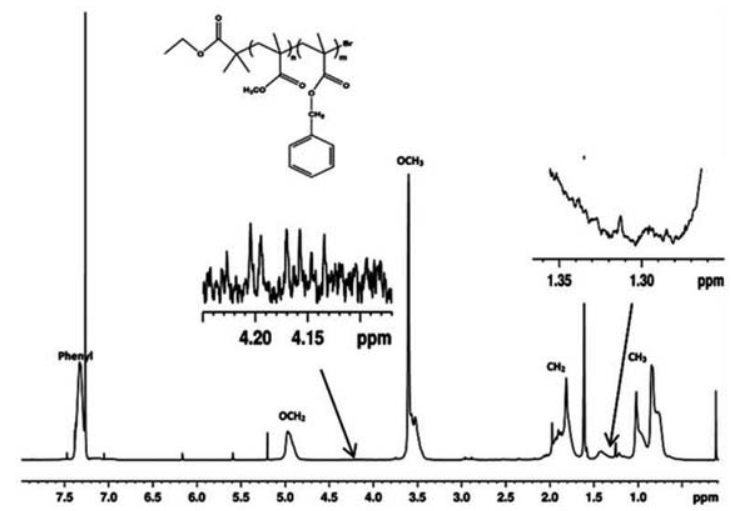

FIGURE 5 (a) ${ }^{1} \mathrm{H}$ NMR of PMMA showing the signals of initiator attached to the polymer chain-end and (b) ${ }^{1} \mathrm{H}$ NMR of copolymer of PMMA-PBMA prepared by using PMMA-Br as macro-initiator under visible light.

the peak weight after the extended chain of PMMA with PBMA $\left(M_{\mathrm{n}, \mathrm{GPC}}=69,250 \mathrm{~g} \mathrm{~mol}^{-1}\right)$. It further confirms the features of controlled/ living radical polymerization of MMA by visible light induced polymerization. The incorporation of MMA and BMA in copolymer has been determined from ${ }^{1} \mathrm{H}$ NMR spectra [Fig. 5(b)]. The peak at $4.9 \mathrm{ppm}$ and $3.5 \mathrm{pm}$ corresponds to $-\mathrm{OCH}_{2}$ and $-\mathrm{OCH}_{3}$ groups of BMA and MMA in copolymer, respectively. The aromatic protons of BMA appears at 7.2-7.4 ppm. The $\mathrm{aCH}_{3}$ and backbone $\mathrm{CH}_{2}$ pro-

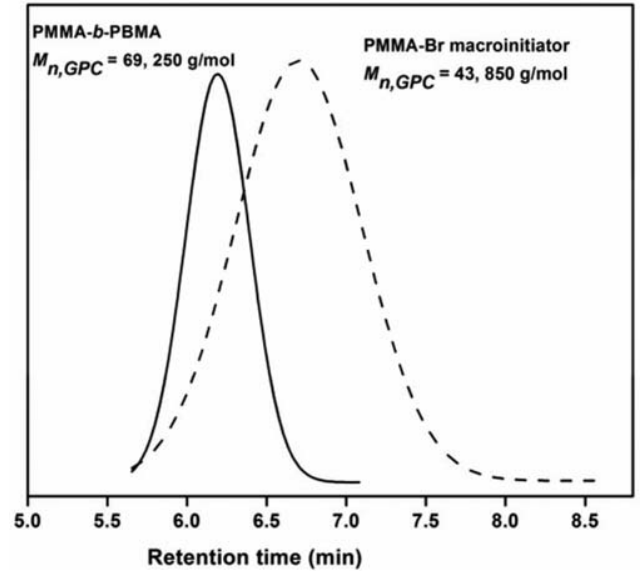

FIGURE 6 Monomodal GPC curves of PMMA-Br macroinitiator before (solid line) and after (dashed) chain extension with BMA.

tons of both BMA and MMA in copolymer resonances at 0.4$1.2 \mathrm{ppm}$ and 1.4-2.1 ppm. In Figure 5(b), the end group peaks are too weak to be identified owing to increased molecular weight of polymer coupled with only one end group. These evidences are indicative of the growing chain ends have bromide groups at the chain ends.

To explain the mechanism of visible light mediated polymerization reaction we have collected XPS spectrum of iron complex 1 before polymerization reaction and in-between the reaction. Figure 7(a) shows the X-ray photoelectron spectrum of iron complex 1 in the Fe $2 p$ regions. The peak for Fe $2 p_{3 / 2}$ and $\mathrm{Fe} 2 \mathrm{p}_{1 / 2}$ in iron complex before polymerization reaction was found to be at 708.848 and $721.497 \mathrm{eV}$, respectively, which indicated that the iron was presented in $\mathrm{Fe}^{+2}$ state. ${ }^{30}$ However, the XPS spectrum of iron complex $\mathbf{1}$ in between the polymerization reaction [Fig. 7(b)], showed the shifting of binding energy values to $711.069 \mathrm{eV}$ and 722.808 $\mathrm{eV}$ for $\mathrm{Fe} 2 \mathrm{p}_{3 / 2}$ and $\mathrm{Fe} 2 \mathrm{p}_{1 / 2}$ respectively. These higher values confirmed that $\mathrm{Fe}(\mathrm{II})$ complex was converted into $\mathrm{Fe}(\mathrm{III})$ after transferring photo excited electron to initiator molecule as shown in Scheme 1. ${ }^{31}$
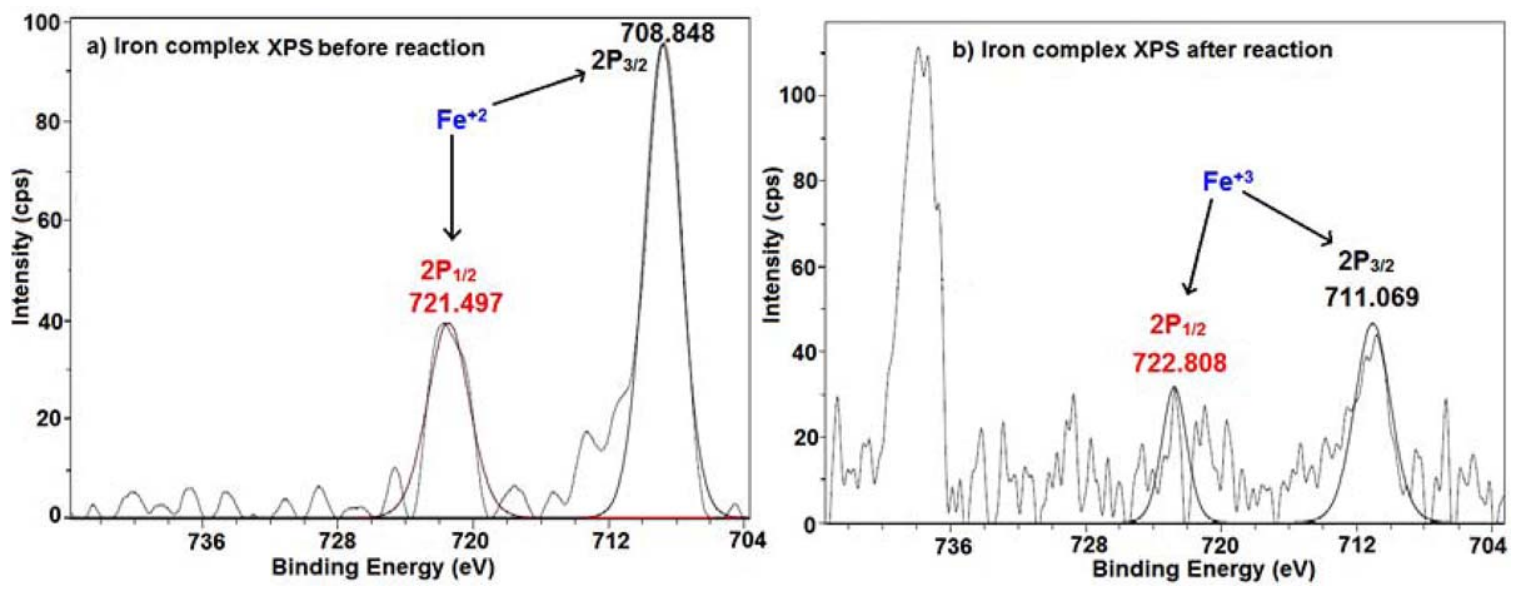

FIGURE 7 XPS spectra of Iron complex 1 in Fe 2p regions; (a) Before reaction; (b) Sample withdrawn during the reaction. [Color figure can be viewed in the online issue, which is available at wileyonlinelibrary.com.] 


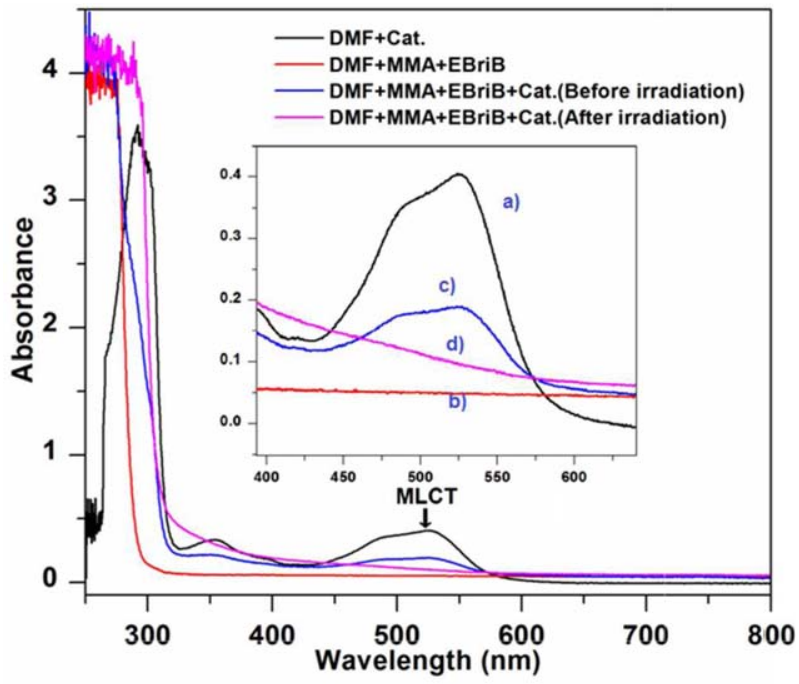

FIGURE 8 UV-vis spectra of (a) DMF $+1\left(6.14 \times 10^{6} \mathrm{M}\right)$; (b) $\mathrm{DMF}+\mathrm{MMA}+\mathrm{EBriB}$; (c) DMF + MMA + EBriB + 1 (before Irradiation); (d) $\mathrm{DMF}+\mathrm{MMA}+\mathrm{EBriB}+1$ (After Irradiation); Insert shows the disappearance of MLCT transition band of complex 1 during the polymerization reaction under visible light. [Color figure can be viewed in the online issue, which is available at wileyonlinelibrary.com.]

Further the transition of iron complex $\mathbf{1}$ from Fe(II) to Fe(III) was confirmed by UV-vis spectroscopic analysis (Fig. 8). The UV-Vis spectra of complex $1\left(6.14 \times 10^{6} \mathrm{M}\right)$ in DMF [Fig. 8(a)] showed characteristics absorption band of [Fe $\left.(\text { bpy })_{3}\right](\mathrm{PF} 6)_{2}$ at $285 \mathrm{~nm}$ due to interligand $\pi \rightarrow \pi^{*}$ transition and a hump at $523 \mathrm{~nm}$ due to the metal to ligand $\mathrm{Fe}(\mathrm{d} \pi) \rightarrow \operatorname{Ligand}\left(\pi^{*}\right)$ transition. $^{29,32}$ The mixture of DMF, MMA, EBriB did not show any peak in visible region Figure 8(b). The addition of complex $\mathbf{1}$ to the above mixture before irradiation revealed a characteristic band due to MLCT transition of Fe complex 1 as shown in Figure 8(c). As the reaction mixture was irradiated in visible light, the band at $523 \mathrm{~nm}$ was found to be reduced with time and was disappeared completely at the end of the reaction [Fig. 8(d)]. This disappearance of band in the reaction mixture after visible

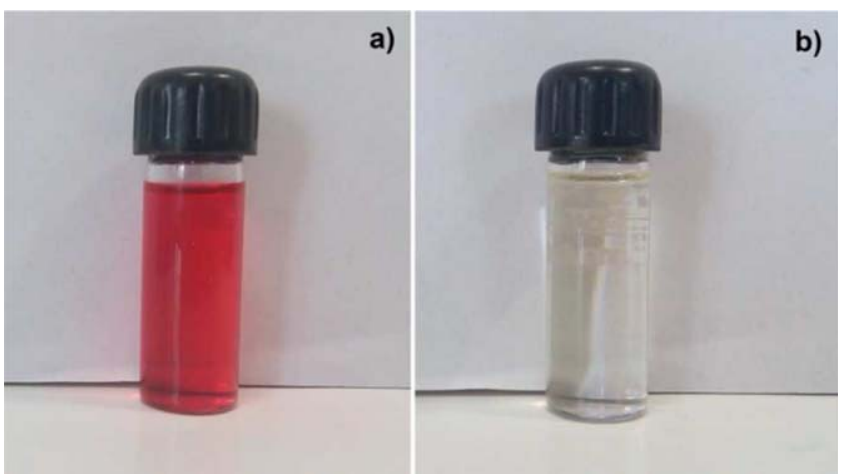

FIGURE 9 Color change of reaction mixture (a) before reaction and (b) after reaction. [Color figure can be viewed in the online issue, which is available at wileyonlinelibrary.com.]
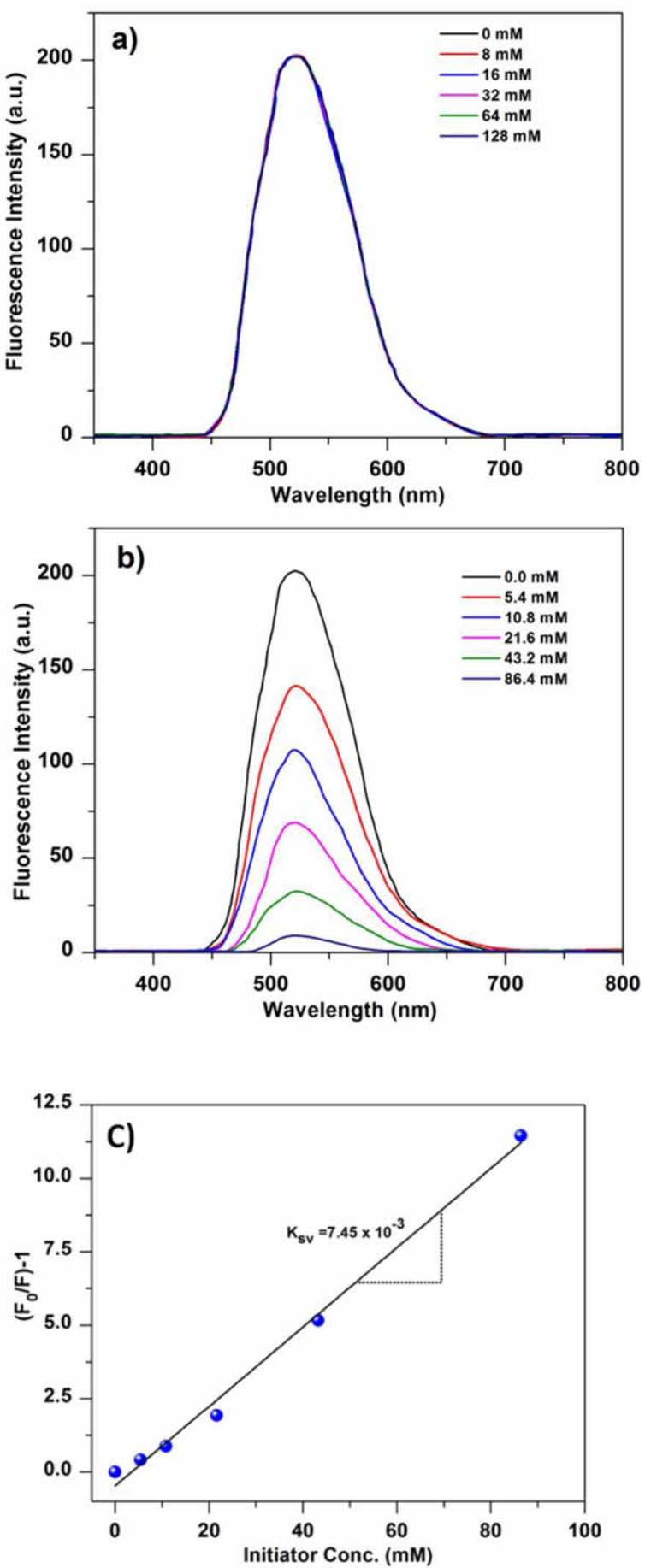

FIGURE 10 Fluoresence quenching studies of complex $1(0.16$ $\mathrm{mmol}$ ) in DMF (a) by varying the concentration of MMA (0-128 mmol), (b) by varying the concentration of Initiator EBriB (0-86.4 mmol) and (c) Stern-Volmer Plot for quenching of complex $1(0.16 \mathrm{mmol})$ by varying the concentration of Initiator EBriB (0-86.4 mmol). [Color figure can be viewed in the online issue, which is available at wileyonlinelibrary.com.]

light irradiation indicated the transition of Fe(II) to Fe(III) species. Furthermore, at the end of the reaction, the mixture became colorless as shown in Figure 9. 
TABLE 2 Iron-Catalyzed Radical Polymerization of Various Methacrylates Under Visible Light ${ }^{\mathrm{a}}$

\begin{tabular}{|c|c|c|c|c|c|}
\hline Entry & Substrate & Conv. $(\%)^{b}$ & $M_{\mathrm{n}}$ & PDI & $M_{\mathrm{n}, \text { theor }}$ \\
\hline 1 & & 90 & 20,200 & 1.27 & 6390 \\
\hline 2 & & 85 & 52,600 & 1.32 & 6870 \\
\hline 3 & & 68 & 87,000 & 1.25 & 7130 \\
\hline 4 & & 65 & 95,500 & 1.33 & 6550 \\
\hline 5 & & 71 & 97,400 & 1.24 & 7140 \\
\hline 6 & & 85 & 22,400 & 1.33 & 8510 \\
\hline
\end{tabular}

a Reaction conditions: [substrate]:[EBriB]:[Fe(bpy $)_{3}{ }^{2+}$ ] $=100: 1.5: 0.03 ; \mathrm{DMF}=$ $50 \%(\mathrm{v} / \mathrm{v})$, visible light; time $24 \mathrm{~h}$.

${ }^{\mathrm{b}}$ Conversion was estimated by precipitating the mixture in methanol.

Furthermore, we carried out the fluorescence quenching (Stern-Volmer quenching) studies to establish the mechanism of the reaction. When the complex $1(0.16 \mathrm{mmol})$ was combined with various concentration of MMA (0-128 mmol) without initiator, no change in the frequency was observed Figure 10(a). However, when the similar experiment was performed in the presence of initiator $(0-86.4 \mathrm{mmol})$, a significant quenching in the frequency was obtained as shown in Figure 10(b). These results suggest that the excited $\mathrm{Fe}(\mathrm{II})^{*}$ complex participates in a redox process with initiator and not reacting with the monomer. To determine the nature of quenching Stern-Volmer graph was plotted by using the following equation.

$$
F_{0} / F=1+K_{\mathrm{SV}}[Q]
$$

where, $F_{0}$ and $F$ are the fluorescence intensities of complex 1 in the absence and presence of initiator EBriB. $K_{\mathrm{SV}}$ and $[Q]$ are the Stern-Volmer quenching constant and concentration of the initiator respectively. A plot between $\left(F_{0} / F\right)-1$ on $X$ axis and initiator concentration $[Q]$ on $Y$ axis gave a straight line which confirmed the dynamic quenching of complex by initiator. The value of Stern-Volmer constant (slope) was found to be $7.45 \times 10^{-3} \mathrm{M}^{-1}$ [Fig. 10(c)].

To check the wide applicability of catalyst for visible light induced polymerization reaction we performed the polymerization of different substituted methacrylates under optimized reaction conditions (Table 2). Among the various substrates studied, methacrylates containing electron withdrawing groups were found to be more reactive and gave higher conversion as compared with those having electron donating groups.

\section{CONCLUSIONS}

We have demonstrated for the first time an efficient visible light mediated catalytic system using low cost iron complex, that is, $\mathrm{Fe}(\mathrm{bpy})_{3}(\mathrm{PF})_{6}$ as photocatalyst that initiates and control the free radical polymerization of methacrylates using ethyl $\alpha$-bromoisobutyrate (EBriB) as an initiator and 20 watt LED as light source. The effect of light flux on photocatalytic polymerization of MMA was investigated by turning on and off the light at every $1 \mathrm{~h}$ interval. It was observed that when light was turned off there were no polymerization occurred but as the light was on the polymerization started again, indicating the living nature of polymerization reaction. The findings presented in this work will help in developing new low cost catalysts for solar assisted polymerization reactions and will help in solving the energy and environmental problems to certain extent.

\section{ACKNOWLEDGMENTS}

Authors would like to thanks Director IIP for granting permission to publish these finding. Analytical department is acknowledged for kind support in analysis of samples. $\mathrm{AB}$ and PK are also thankful to CSIR, New Delhi for providing research fellowships

\section{REFERENCES AND NOTES}

1 V. Mishra, R. Kumar, J. Sci. Res. 2012, 56, 141-176.

2 Z. Guan, B. Smart, Macromolecules 2000, 33, 6904-6906.

3 (a) S. Yamago, Y. Nakamura, Polymer 2013, 54, 981-994; (b). Q. Liu, L. Liu, Y. Ma, C. Zhao, W. Yang, J. Polym. Sci. Part A Polym. Chem. 2014, 52, 3283-3291; (c) X. Zhang, C. Zhao, Y. Ma, H. Chen, W. Yang, Macromol. Chem. Phys. 2013, 214, 2624-2631; (d). J. Xu, K. Jung, A. Atme, S. Shanmugam, C. Boyer, J. Am. Chem. Soc. 2014, 136, 5508-5519; (e). H. Chen, C. Zhao, R. Li, Y. Ma, L. Liu, W. Yang, Macromol. Chem. Phys. 2014, 215, 1378-1387.

4 M. A. Tasdelen, M. Ciftci, Y. Yagci, Macromol. Chem. Phys. 2012, 213, 1391-1396.

5 A. E. Muftuoglu, I. Cianga, S. Yurteri, Y. Yagci, J. Appl. Polym. Sci. 2004, 93, 387-394.

6 G. Zhang, I. Y. Song, K. H. Ahn, T. Park, W. Choi, Macromolecules 2011, 44, 7594-7599.

7 B. P. Fors, C. J. Hawker, Angew. Chem. Int. Ed. 2012, 51, 8850-8853.

8 N. J. Treat, H. Sprafke, J. W. Kramer, P. G. Clark, B. E. Barton, J. R. de Alaniz, B. P. Fors, C. J. Hawker, J. Am. Chem. Soc. 2014, 136, 16096-16101.

9 A. Albini, M. Fagnoni, ChemSusChem. 2008, 1, 63-66.

10 C. Grotzinger, D. Burget, P. Jacques, J. P. Fouassier, Polymer 2003, 44, 3671-3677.

11 M. Wang, J. K. Oh, T. E. Dykstra, X. Lou, G. D. Scholes, M. A. Winnik, Macromolecules 2006, 39, 3664-3672.

12 Q. J. Cai, G. D. Fu, F. R. Zhu, E. T. Kang, K. G. Neoh, Angew. Chem. Int. Ed. 2005, 44, 1104-1107.

13 S. Yamaguchi, T. Fukuraa, K. Takiguchi, C. Fujita, M. Nishibori, Y. Teraoka, H. Yahiro, Catal. Today 2012, 242, 261-267.

14 E. P. Talsi, K. P. Bryliakov, Coord. Chem. Rev. 2012, 256, 1418-1434.

$15 \mathrm{~J}$. Li, W. Ma, Y. Huang, X. Tao, J. Zhao, Y. Xu, Appl.Catal. B 2004, 48, 17-24.

16 M. Cheng, W. Ma, C. Chen, J. Yao, J. Zhao, Appl. Catal. B 2006, 65, 217-226. 
17 P. Du, R. Eisenberg, Energy Environ. Sci. 2012, 5, 60126021.

18 S. Gazi, R. Ananthakrishnan, N. D. P. Singh, J. Hazard. Mater. 2010, 183, 894-901.

$19 \mathrm{~J} . \mathrm{Li}, \mathrm{W} . \mathrm{Ma}, \mathrm{Y}$. Huang, M. Cheng, J. Zhao, J. C. Yu, Chem. Commun. 2003, 2214-2215.

20 C. Sun, C. Chen, W. Ma, J. Zhao, Phys. Chem. Chem. Phys. 2011, 13, 1957-1969.

21 S. Caramori, J. Husson, M. Beley, C. A. Bignozzi, R. Argazzi, P. C. Gros, Chem. Eur. J. 2010, 16, 2611-2618.

22 (a) A. Bansal, A. Kumar, P. Kumar, S. Bojja, A. K. Chatterjee, S. S. Ray, S. L. Jain, RSC Adv. 2015, 5, 21189-21196; (b). A. Bansal, S. S. Ray, A. K. Chatterjee, J. Polym. Res. 2015, 22, 23.

23 (a) P. Kumar, S. Varma, S. L. Jain, J. Mater. Chem. A 2014, 2, 4514-4519; (b) P. Kumar, G. Singh, D. Tripathi, S. L. Jain, RSC Adv. 2014, 4, 50331-50337; (c) P. Kumar, A. Bansiwal, N. Labhsetwarb, S. L. Jain, Green Chem. 2015, 17, 1605-1609.

24 P. Kumar, A. Kumar, S. Bojja, B. Sain, S. S. Ray, S. L. Jain, Chem. Eur. J. 2014, 20, 6154-6161.

25 K. Matyjaszewski, M. Wei, J. Xia, N. E. McDermott, Macromolecules, 1997, 30, 8161-8164.

26 M. A. Tehfe, J. Lalevee, F. M. Savary, B. Graff, N. Blanchard, J. P. Fouassier, Macromolecules, 2012, 45, 1746-1752.
27 M. Kamigaito, T. Ando, M. Sawamoto, Chem. Rev. 2001, 101, 3689-3745.

28 J. Lalevee, M. Ali Tehfe, A. Z. Fakih, B. Ball, S. Telitel, F. M. Savary, B. Graff, J. P. Fouassier, ACS Macro Lett. 2012, 1, 802-806.

29 E. M. Kober, T. J. Meyer, Inorg. Chem. 1982, 21, 3967.

30 (a) M. Aronniemi, J. Lahtinen, P. Hautojarvi, Surf. Interface Anal. 2004, 36, 1004-1006; (b) J. L. Magalhaes, L. M. Moreira, U. P. R.-Filho, M. J. Giz, M. A. P.-da-Silva, R. Landers, R. C. G. Vinhas, P. A. P. Nascente, Surf. Interface Anal. 2002, 33, 293 298; (c) T. Matrab, M. Save, B. Charleux, J. Pinson, E. C.-deliry, A. Adenier, M. M. Chehimi, M. Delamar, Surf. Sci. 2007, 601, 2357-2366; (d) R. V. Siriwardane, J. A. Poston Jr., E. P. Fisher, M. S. Shen, A. L. Miltz, Appl. Surf. Sci. 1999, 52, 219-236.

31 (a) H. Wu, G. Gao, X. Zhou, Y. Zhang, S. Guo, Cryst. Eng. Commun. 2012, 14, 499-504; (b) M. Descostes, F. Mercier, N. Thromat, C. Beaucaire, M. G.-Soyer, Appl. Surf. Sci. 2000, 165, 288-302; (c) X. Li, W. Zhang, J. Phys. Chem. C 2007, 111, 69396946; (d) H. Yu, H. Irie, Y. Shimodaira, Y. Hosogi, Y. Kuroda, M. Miyauchi, K. Hashimoto, J. Phys. Chem. C 2010, 114, 1648116487.

32 D. W. Thompson, A. Ito, T. J. Meyer, Pure Appl. Chem. 2013, 85, 7, 1257-1305. 